\title{
The relationship between catastrophic health expenditure and health-related quality of life
}

\author{
Seung Hyun Kang ${ }^{1}$, Yeong Jun Ju ${ }^{1,2}$, Hyo Jung Yoon ${ }^{1,2}$, Sang Ah Lee ${ }^{1,2}$, Woorim Kim ${ }^{1,2}$ and Eun-Cheol Park ${ }^{2,3^{*}}$ (D)
}

\begin{abstract}
Objectives: The objective of our study was to investigate the relationship between catastrophic health expenditure (CHE) and health-related quality of life (HRQOL) in general population.

Methods: We used Korean Health Panel Survey data from 2011 to 2013, which included data from 8850 baseline participants of 19 years of age or older. We defined CHE as total annual out-of-pocket health payment that was $40 \%$ greater than the household's capacity to pay. HRQoL was measured using the EuroQol-visual analogue scale (EQ-VAS). We used generalized estimating equations to perform a longitudinal regression analysis.
\end{abstract}

Results: A total of $4.5 \%$ of the participants $(n=398)$ experienced CHE. Those with CHE tended to have a lower EQ-VAS index score compared with those without CHE ( $\beta:-1.34, p=0.013)$. A subgroup analysis revealed that individuals experiencing $\mathrm{CHE}$ had significant decreases as the number of chronic diseases increased (three or more, $\beta:-1.85, p=0.014)$.

Conclusions: Catastrophic health expenditure influences HRQoL, which was more pronounced in patient with chronic disease. The efforts should focus on people who suffer from excessive health expenditures and chronic diseases.

Keywords: Catastrophic health expenditure, Health-related quality of life, Out-of-pocket health payment, Chronic disease

\section{Introduction}

Health-related quality of life (HRQoL) is a multi-dimensional concept that includes domains related to physical, mental, emotional, and social functioning and the social context in which people live [1]. HRQoL is an important outcome used in a variety of medical research disciplines to ascertain aspects of well-being in settings of health and disease. Since 1949, the World Health Organization (WHO) has emphasized the importance of HRQoL [2]. The WHO's 'Healthy People 2020' initiative emphasizes HRQoL as one of its four overarching goals [3].

\footnotetext{
* Correspondence: ecpark@yuhs.ac

${ }^{2}$ Institute of Health Services Research, Yonsei University, Seoul, Republic of Korea

${ }^{3}$ Department of Preventive Medicine and Institute of Health Services Research, Yonsei University College of Medicine, 50 Yonsei-ro,

Seodaemun-gu, Seoul 03722, Korea

Full list of author information is available at the end of the article
}

As factors affecting HRQoL vary, HRQoL has been analyzed as an outcome in a variety of populations and settings [4]. Previous studies to clarify the factors affecting HRQoL have generally considered physical functioning (e.g., overall physical health, physical functioning, pain, fatigue), disease-specific (e.g., cancer, chronic disease), health care service use (e.g., unmet healthcare needs) factors as relevant [5-9]. In particular, not only burden for clinical status but also socio-economic burden can also affect HRQoL. For example, financial hardship was associated with degenerated physical and psychological heath, thereby exacerbating HRQoL [10]. In addition, financial hardship that occurs after receiving hematopoietic cell transplantation was associated with worse quality of life and exacerbated perceived stress [11]. Studies on this topic have focused primarily on specific disease with high medical expenditures such as cancer. On the other hands, in line with the increasing trend of socio-economic burden of chronic disease such 
as non-communicable disease [12], study reported that high medical expenditure including out-of-pocket expenditure in type 2 diabetic patients was associated to poor health-related quality of life [13]. Especially, household members with chronic illness are the major factors affecting financial catastrophe, financial hardship of healthcare was greater for subjects affected by chronic disease than those unaffected [14-16]. Hence, catastrophic healthcare expenditure which implies a financial hardship due to medical expenditure may impact on health-related quality of life. Only a few studies have addressed this issue. This topic is especially relevant to countries with concerns about health-related life satisfaction and health service utilization.

In Korea, subjective health satisfaction is the lowest among all OECD countries. According to an OECD report, only $35.1 \%$ of Koreans $\geq 15$ years of age believe their health condition to be "good". This value is approximately one-half the OECD average of $69.2 \%$. Hence, it is necessary to examine health-related life satisfaction issues in terms of promotion and identification of the factors that affect HRQoL. In addition, a national health insurance system provides universal healthcare coverage in Korea, but there are barriers to medical care access because high out-of-pocket payments (OOP) cause catastrophic health expenditures (CHEs). Overall, the South Korean OOP payment for healthcare is the highest among OECD countries (Korea: 4.7\%; OECD average: $2.8 \%$ ) [17]. Korea also has a relatively greater proportion of households with catastrophic expenditures $[17,18]$.

Therefore, the present study used longitudinal data and analysed the effects of catastrophic health expenditure on HRQoL in the general population. In addition, we examined the relationship between CHE and HRQoL by number of chronic disease.

\section{Materials and methods Study population}

We used raw data from the Korean Health Panel Study (KHPS) conducted in 2008 and 2013. The group of study participants was a nationally representative sample of Korean. The KHPS is a panel survey conducted annually by the Korean Institute for Health and social Affairs in conjunction with the National Health Insurance service on a nationally representative sample of South Korean household. Households are selected using a stratified multistage probability sampling design in order to select nationwide subjects. The KHPS comprised three parts-household, individual, and case-based sections-all of which were performed by trained medical staff through a computer assisted personal interviewing. The household survey included questions about general characteristics, living expenses, pharmaceutical product purchases, and private health insurance with associated premiums. The individual survey considered the demographic characteristics of the subjects. The case-based survey was designed only for individuals with chronic diseases and those receiving inpatient treatment, outpatient treatment, or emergency-service utilization. We used data from all three surveys. Detail of the datasets are available at https://www.khp.re.kr:444/eng/main.do.

The KHPS began in 2008, but the monthly food expense variable used to calculate CHE was recorded beginning in 2011. Thus, we used data from the KHPS between 2011 and 2013. In addition, KHPS was released to raw data until 2015, but EQ-VAS was not measured in 2014 and 2015, so it was not used in the analysis. Our sample was restricted to individuals aged 19 years or older. To analysis only newly onset catastrophic health expenditure, we excluded respondents who responded that they experienced catastrophic health expenditure in 2011. Of the 12,683 in 2011, subjects with catastrophic health expenditure and without follow-up in 2012 were not included in the analysis; 1838 participants were excluded. Then 10,845 subjects were followed up in 2012. Of the 10,845 subjects in 2012, after excluding subjects with any missing values or without follow-up in 2013, a total of 8850 subjects remained in this study. Thus, baseline included 8850 subjects with a 2 -year follow-up (see details in Fig. 1).

We used public KHPS data, which did not include any information that could be used to identify individuals. The survey's design and methods conformed to local regulations and Declaration of Helsinki standards. The data, and the permission to use and analyze the data, were provided by KIHASA.

\section{Measures}

\section{Health-related quality of life}

We measured HRQoL using the EuroQoL-visual analogue scale (EQ-VAS) index. EQ-VAS is a self-rated health questionnaire presented as a vertical visual "thermometer" with end-point values of 100 (best imaginable HRQoL) and 0 (worst imaginable HRQoL). Higher scores correspond to a higher HRQoL.

\section{Catastrophic health expenditure}

We used the WHO standard threshold to define CHE as a total annual OOP health payment that is $40 \%$ greater than the household's capacity to pay [19].

The capacity to pay is defined as the economic power to which a household can purchase a particular goods or service, except for expenditure necessary for a living. We used $\mathrm{Xu}$ et al.'s measure to define the capacity to pay as the amount of money available after excluding food expenses [20]. The monthly food expenditure was deducted from the monthly living expenditure, and then 


\section{Korean Health Panel Survey}

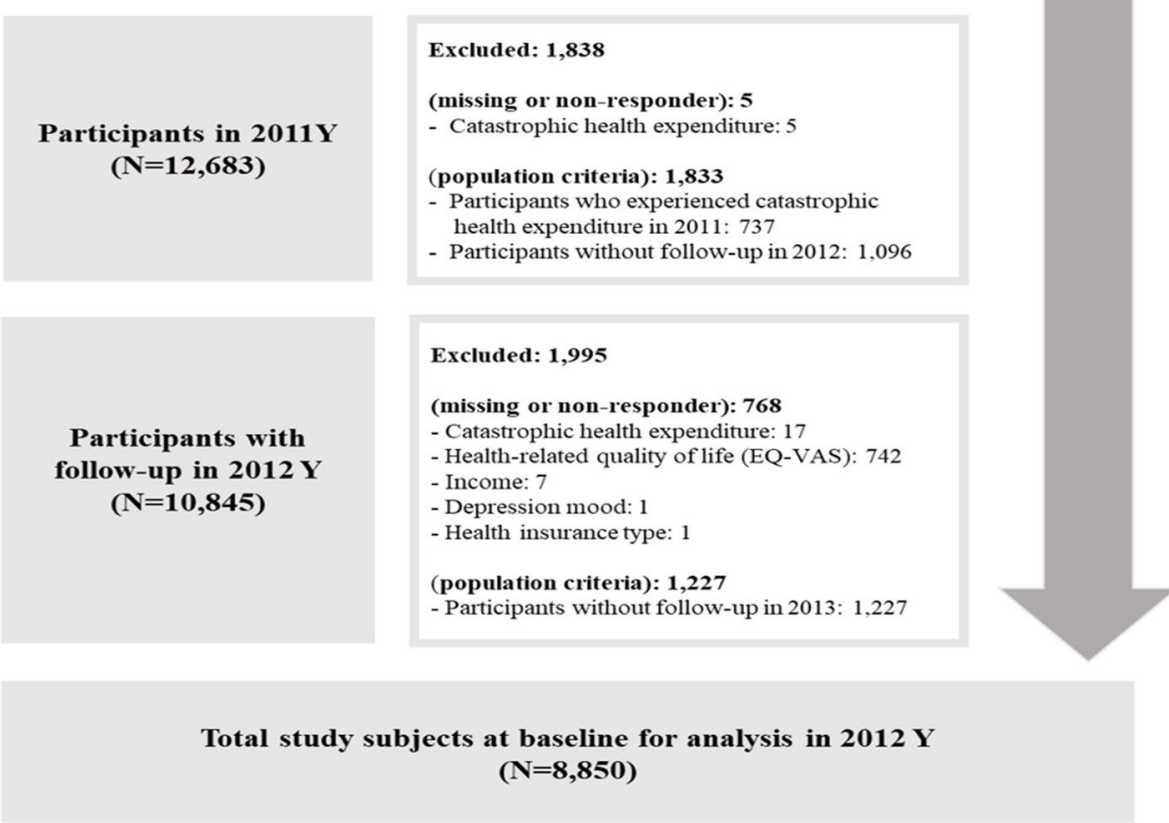

Fig. 1 Flow chart of participant selection process

multiplied by 12 to obtain the yearly payment conversion.

The OOP was defined as medical expenses borne by the family at the time of receiving the health care services as defined by the WHO [19]. The annual OOP health payment was calculated by including medical and drug costs resulting from emergency, outpatient care, and hospitalization, services. Indirect medical costs (e.g., including transportation or nursing costs) were excluded from the calculation.

$\mathrm{CHE}=\frac{\text { household } \text { out }- \text { of }- \text { pocket health expenditure }}{\text { household expenditure (excluding food expenses })}>40 \%$

\section{Covariates}

We included several demographic, socioeconomic, and health-related variables as covariates. The demographic variables included sex and age. The socioeconomic variables included education level (elementary school or below, middle school or high school, college or above), economic activity (employed, unemployed), family constitution (living alone, couple, couple with child, more), health insurance type (health insurance, medical aid), and income (low, low-middle, middle, middle-high, high). The health-related variables were the number of chronic diseases, disability (yes, no), how perceive health status (good, bad), depressive mood during the past 2 weeks (present, absent). Survey year was included as a covariate.

\section{Statistical analysis}

Descriptive statistics were presented as number of subjects and proportions. Univariate analyses were performed to compare the mean EQ-VAS score values for two groups using $T$-test as well as analysis of variance (ANOVA) were performed to compare the mean EQ-VAS score values among the three or more groups. We evaluated the relationship between catastrophic health expenditure and HRQoL using a generalized estimating equation (GEE) model that was an extension of the quasi-likelihood approach used to analyses longitudinal correlated data [21]. The GEE model was used for analyzing longitudinal data, as it accounted for time variation and correlations between repeated measurements. In details, the statistical analyses were performed using the GENMOD procedure. It computes robust standard error estimates by default and accounts for the correlations among repeated measurements [22]. All independent variables were adjusted. Finally, a subgroup analysis was performed to evaluate a possible association between catastrophic health expenditure and HRQoL stratified by number of chronic disease. 
The analyses were performed using SAS 9.4 (SAS Institute, Cary, North Carolina, USA) and $p$-values were two-sided and considered significant at $p<.05$.

\section{Results}

In our study, 8850 subjects were included to assess the association between catastrophic health expenditure and health-related quality of life. Table 1 shows the baseline characteristics of the study population. Among the 8850 subjects, $4.5 \%(n=398)$ experienced catastrophic health expenditure. The mean baseline EQ-VAS score was $70.76 \pm 15.39$. The EQ-VAS score value was lower for those who experienced CHE $(64.46 \pm 17.56)$ compared with those who did not experience CHE $(71.06 \pm 15.21)$. Lower scores indicated more severe status in HRQoL.

Table 2 shows the association between CHE experiencing and HRQoL while adjusting for all independent variables. Those with CHE experiencing tended to have lower EQ-VAS index values compared with those without CHE ( $\beta:-1.34, p=0.013)$. A more detailed examination of the relationship between experiencing $\mathrm{CHE}$ and HRQoL revealed that respondents $\geq 70$ years of age tended to have lower EQ-VAS index values compared with respondents 19 29 years of age $(\beta:-1.72$, $p=0.010)$. An examination based on income revealed that EQ-VAS values increased as income increased (i.e., low < middle-low < middle < middle-high $<$ high; low: 3.26, middle-low: -1.69 , middle: -1.75 , middle-high: 0.94). Respondents with $\geq 3$ chronic diseases had lower EQ-VAS scores compared with those without any chronic diseases $(\beta:-3.11, p<0.001)$.

The subgroup analysis results are shown in Table 3. Subjects with $\mathrm{CHE}$ and greater chronic disease (3 or more) exhibited a drastic decrease in HRQoL.

\section{Discussion}

We found that after adjustment for multiple variables, CHE was significantly associated with degenerated HRQoL in the general population. The results of our subgroup analysis indicated that the association between CHE and HRQoL was stronger in individuals with chronic disease.

These findings can be explained by the associations between financial burden and life satisfaction. Previous studies have examined the associations between economic hardship and life satisfaction and have found that financial burden has adverse consequences on life satisfaction characteristics [23-25]. Studies of catastrophic expenditure revealed that there is a robust association between excessive expenditure for healthcare and financial strain (e.g., onset of poverty). Hence, experiencing CHE may increase financial strain and result in a deteriorating HRQoL.
Consistent with previous studies on financial hardship, cancer survivors in the USA who have financial burdens (e.g., borrowed money) are more likely to have low Physical Component and Mental Component scores and are therefore more likely to experience a depressed mood [26]. Patients in the UK who have head and neck cancer that has resulted in serious effects on household finances have poor HRQoL [27].

Populations who suffer from a chronic disease are more likely to experience CHE because medical expenditures are likely to continue for a long period. As expenditures for chronic disease treatment accumulate, individuals or households are more likely to compromise healthy lifestyle choices. For example, they cannot afford fresh fruits and vegetables, which are more expensive than processed foods [28]. Therefore, chronic disease has the potential to negatively affect health-related life satisfaction characteristics [29]. This phenomenon has been found in developing [30] countries and in the wealthiest countries in Europe [31].

Our study revealed that $4.5 \%$ of households in Korea experienced CHE. This estimate is similar to the 3.0\% that the OECD reported for 2012 using Korea national statistics. This value is also the highest among OECD countries [32]. Among developed countries, only Portugal, Greece, Switzerland, and the United States have $0.5 \%$ or more of households with catastrophic-level health spending. OOP payments for healthcare can cause households to incur catastrophic expenditures [33, 34]. Therefore, this result for Korea is expected because OOP spending as a share of total health expenditure is relatively high $($ Korea $=36 \%$; OECD average $=19 \%)$ [35]. High OOP payments may create barriers to medical utilization that cause delays in care, low screening rates among vulnerable people, and exacerbate inequities in health status and in health-related life satisfaction characteristics.

Even when we excluded households that experienced CHE in the most recent year, the mean EQ-VAS score at baseline was 70.8; this value was less than that of the general population of China (80.1) [36] and of the mean overall score of six European countries (77.1) [37]. South Korea currently has serious life satisfaction issues. Koreans are substantially less satisfied with their lives compared with residents of OECD countries. The 'Better Life Index' report presents results for eleven parameters (e.g., income, jobs, health and work-life balance); Korea ranked 29th among OECD countries in 2014 (Korea's score: 5.8/10; OECD average: 6.6/10). The results for the self-reported health measure of health-related life satisfaction indicated that individual South Korean 
Table 1 General characteristics of study population at baseline in 2012

\begin{tabular}{|c|c|c|c|c|c|}
\hline \multirow[t]{2}{*}{ Variables } & \multicolumn{5}{|c|}{ EQ-VAS } \\
\hline & $\mathrm{N}$ & (\%) & Mean \pm S.D & t / F value & $p$-value \\
\hline \multicolumn{4}{|c|}{ Catastrophic expenditure } & -7.37 & $<.0001$ \\
\hline Yes & 398 & $(4.5)$ & $64.46 \pm 17.56$ & & \\
\hline No & 8452 & $(95.5)$ & $71.06 \pm 15.21$ & & \\
\hline \multicolumn{4}{|l|}{ Sex } & 8.42 & $<.0001$ \\
\hline Male & 3834 & $(43.3)$ & $72.32 \pm 14.72$ & & \\
\hline Female & 5016 & $(56.7)$ & $69.57 \pm 15.78$ & & \\
\hline \multicolumn{4}{|l|}{ Age } & 104.34 & $<.0001$ \\
\hline $19 \sim 29$ & 733 & $(8.3)$ & $75.19 \pm 14.60$ & & \\
\hline $30 \sim 39$ & 1421 & $(16.1)$ & $73.56 \pm 14.55$ & & \\
\hline $40 \sim 49$ & 2057 & $(23.2)$ & $73.65 \pm 13.37$ & & \\
\hline $50 \sim 59$ & 1693 & $(19.1)$ & $70.86 \pm 14.55$ & & \\
\hline $60 \sim 69$ & 1503 & $(17.0)$ & $68.36 \pm 16.03$ & & \\
\hline $70+$ & 1443 & $(16.3)$ & $64.03 \pm 16.88$ & & \\
\hline \multicolumn{4}{|l|}{ Education level } & 281.25 & $<.0001$ \\
\hline $\begin{array}{l}\text { Elementary or } \\
\text { below }\end{array}$ & 1912 & $(21.6)$ & $64.16 \pm 16.87$ & & \\
\hline $\begin{array}{l}\text { Middle/high } \\
\text { school }\end{array}$ & 3955 & $(44.7)$ & $71.14 \pm 14.85$ & & \\
\hline College or above & 2983 & $(33.7)$ & $74.49 \pm 13.63$ & & \\
\hline \multicolumn{4}{|l|}{ Economic status } & 10.29 & $<.0001$ \\
\hline Employed & 5498 & $(62.1)$ & $72.11 \pm 14.46$ & & \\
\hline Unemployed & 3352 & $(37.9)$ & $68.55 \pm 16.56$ & & \\
\hline \multicolumn{4}{|l|}{ Income } & 117.73 & $<.0001$ \\
\hline Low & 1243 & $(14.0)$ & $63.41 \pm 17.67$ & & \\
\hline Middle-low & 1687 & $(19.1)$ & $69.08 \pm 15.39$ & & \\
\hline Middle & 1866 & $(21.1)$ & $71.25 \pm 14.82$ & & \\
\hline Middle-high & 1987 & $(22.4)$ & $72.56 \pm 14.56$ & & \\
\hline High & 2067 & $(23.4)$ & $74.38 \pm 13.41$ & & \\
\hline \multicolumn{4}{|l|}{ Health insurance type } & 12.17 & $<.0001$ \\
\hline Health insurance & 8448 & $(95.5)$ & $71.30 \pm 14.96$ & & \\
\hline Medical aid & 402 & $(4.5)$ & $59.39 \pm 19.34$ & & \\
\hline \multicolumn{4}{|l|}{ Family constitution } & 79.65 & $<.0001$ \\
\hline Living alone & 667 & $(7.5)$ & $66.46 \pm 17.12$ & & \\
\hline Couple & 1792 & $(20.3)$ & $68.06 \pm 16.37$ & & \\
\hline $\begin{array}{l}\text { Couple with } \\
\text { children }\end{array}$ & 4803 & $(54.3)$ & $73.00 \pm 14.11$ & & \\
\hline More & 1588 & $(17.9)$ & $68.87 \pm 16.06$ & & \\
\hline \multicolumn{4}{|c|}{ Number of chronic disease } & 225.56 & $<.0001$ \\
\hline 0 & 3180 & $(35.9)$ & $74.92 \pm 13.73$ & & \\
\hline 1 & 1794 & $(20.3)$ & $72.41 \pm 14.19$ & & \\
\hline 2 & 1252 & $(14.1)$ & $70.00 \pm 15.11$ & & \\
\hline $3+$ & 2624 & $(29.7)$ & $64.96 \pm 16.34$ & & \\
\hline
\end{tabular}

Table 1 General characteristics of study population at baseline in 2012 (Continued)

\begin{tabular}{|c|c|c|c|c|c|}
\hline \multirow[t]{2}{*}{ Variables } & \multicolumn{5}{|c|}{ EQ-VAS } \\
\hline & $\bar{N}$ & (\%) & Mean \pm S.D & $t / F$ value & $p$-value \\
\hline Disability & & & & 12.77 & $<.0001$ \\
\hline Absent & 8266 & (93.4) & $71.38 \pm 15.04$ & & \\
\hline Present & 584 & (6.6) & $61.95 \pm 17.40$ & & \\
\hline Perceive health status & & & & 40.78 & $<.0001$ \\
\hline Good & 7478 & $(84.5)$ & $73.72 \pm 13.20$ & & \\
\hline Bad & 1372 & $(15.5)$ & $54.62 \pm 16.41$ & & \\
\hline Depression mood & & & & -18.53 & $<.0001$ \\
\hline Present & 632 & $(7.4)$ & $58.11 \pm 18.03$ & & \\
\hline Absent & 8218 & (92.9) & $71.74 \pm 14.72$ & & \\
\hline Year & & & & & \\
\hline 2012 & 8850 & 100.0 & $70.76 \pm 15.39$ & & \\
\hline
\end{tabular}

citizens have the least confidence in their own health condition level. Taken together, these findings indicate that effective strategies to manage HRQoL among households with CHE should be designed and implemented.

Our findings suggested that programs (e.g., medical expense assistance) that support populations who experience CHE are needed to improving the quality of life. The Korean government recently implemented the pilot catastrophic healthcare expenditure aid program. This public assistance program targets poor individuals who experience catastrophic healthcare expenditure due to major severe diseases (e.g., cancer, cardiovascular disease, rare diseases).

We suggest that countries with low financial assistance levels for healthcare should aim to reduce the barriers within the healthcare system and allocate resources to strengthen healthcare coverage and increase healthcare equity. These efforts should emphasize guarantee of healthcare services for people who suffer from excessive health expenditures and chronic disease.

This study had some limitations. First, the EQ-VAS measures current health status and CHE was measured using yearly health expenditure data. Therefore, the effects from external events might have moderated or reinforced the HRQoL results. Second, we used the EQ-VAS to measure HRQoL, which depends on the participant's subjective perception. However, the EQ-VAS is widely used for HRQoL studies. Third, due to limitations of our data, we measured short-term effects (i.e., 2 years). Further studies of longer-term effects of CHE are needed.

Despite the limitations, this study is the first to investigate associations between $\mathrm{CHE}$ and HRQoL 
Table 2 Results of the GEE analyzing for the effect of catastrophic health expenditure on EQ-VAS

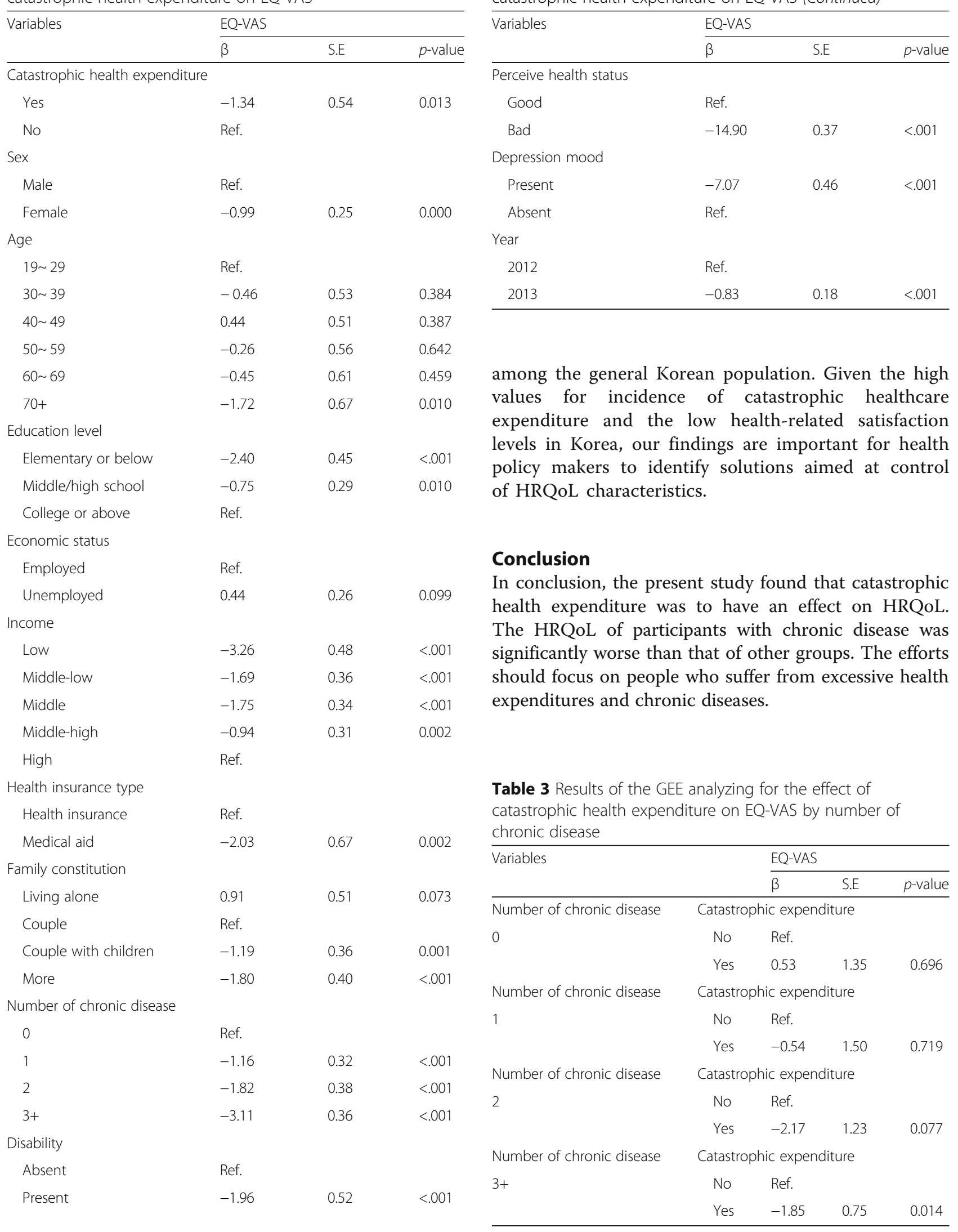

Table 2 Results of the GEE analyzing for the effect of catastrophic health expenditure on EQ-VAS (Continued)

among the general Korean population. Given the high policy makers to identify solutions aimed at control

.




\section{Abbreviations}

CHE: Catastrophic health expenditure; EQ-VAS: EuroQoL-Visual analogue scale; HRQoL: Health related quality of life; KHPS: Korea health panel study; OOP: Out-of-pocket payments; WHO: World Health Organization

\section{Acknowledgements}

None.

\section{Funding}

None.

\section{Availability of data and materials}

The dataset is available on the Korea Health Panel Survey website: https://www.khp.re.kr:444/eng/data/data.do.

\section{Authors' contributions}

$\mathrm{SH}$ managed and analyzed data and wrote the manuscript. YJ and $\mathrm{HJ}$ contributed to analysis the data and manuscript writing. SA, and W provided intellectual input for the development of the manuscript. EC designed and supervised the present study. All authors read and approved the final manuscript.

\section{Ethics approval and consent to participate}

The Korea Health Panel Survey data is openly published. Thus, ethical approval was not required for this study. This study did not require informed consent from the participants, as their information was fully anonymized and unidentified prior to analysis.

\section{Consent for publication}

Not applicable.

\section{Competing interests}

The authors declare that they have no competing interests.

\section{Publisher's Note}

Springer Nature remains neutral with regard to jurisdictional claims in published maps and institutional affiliations.

\section{Author details}

${ }^{1}$ Department of Public Health, Graduate School, Yonsei University, Seoul, Republic of Korea. ${ }^{2}$ Institute of Health Services Research, Yonsei University, Seoul, Republic of Korea. ${ }^{3}$ Department of Preventive Medicine and Institute of Health Services Research, Yonsei University College of Medicine, 50 Yonsei-ro, Seodaemun-gu, Seoul 03722, Korea.

Received: 25 May 2018 Accepted: 30 October 2018

Published online: 14 November 2018

\section{References}

1. Ferrans CE. Definitions and conceptual models of quality of life. In: Outcomes Assessment in cancer: Measures, Methods, and Applications; 2005. p. 14-30.

2. Grad FP. The preamble of the constitution of the World Health Organization. Bull World Health Organ. 2002;80:981

3. Department of Health and Human Services. Healthy people 2020 framework: The Vision, Mission and goals of healthy people 2020. Washington, DC: Office of Disease Prevention and Health Promotion; 2012

4. McHorney CA. Health status assessment methods for adults: past accomplishments and future challenges 1. Annu Rev Public Health. 1999:20: 309-35

5. Wei JT, Dunn RL, Litwin MS, Sandler HM, Sanda MG. Development and validation of the expanded prostate cancer index composite (EPIC) for comprehensive assessment of health-related quality of life in men with prostate cancer. Urology. 2000;56:899-905.

6. Ghezzi P, Magnanini S, Rinaldini M, Berardi F, Di Biagio G, Testare F, Tavoni N, Schittulli F, D'Amico C, Pedicini T. Impact of follow-up testing on survival and health-related quality of life in breast cancer patients: a multicenter randomized controlled trial. JAMA. 1994:271:1587-92.

7. Marinus J, Ramaker C, van Hilten JJ, Stiggelbout AM. Health related quality of life in Parkinson's disease: a systematic review of disease specific instruments. J Neurol Neurosurg Psychiatry. 2002;72:241-8.
8. El Achhab Y, Nejjari C, Chikri M, Lyoussi B. Disease-specific health-related quality of life instruments among adults diabetic: a systematic review. Diabetes Res Clin Pract. 2008;80:171-84.

9. Ju YJ, Kim TH, Han K-T, Lee HJ, Kim W, Ah Lee S, Park E-C. Association between unmet healthcare needs and health-related quality of life: a longitudinal study. Eur J Public Health. 2017;27:631-7.

10. Kahn JR, Pearlin LI. Financial strain over the life course and health among older adults. J Health Soc Behav. 2006;47:17-31.

11. Abel GA, Albelda R, Khera N, Hahn T, Coronado DYS, Odejide OO, Bona K, Tucker-Seeley R, Soiffer R. Financial hardship and patient-reported outcomes after hematopoietic cell transplantation. Biol Blood Marrow Transplant. 2016; 22:1504-10.

12. Jan S, Laba T-L, Essue BM, Gheorghe A, Muhunthan J, Engelgau M, Mahal A, Griffiths U, Mclntyre D, Meng Q. Action to address the household economic burden of non-communicable diseases. Lancet. 2018:391:2047-58.

13. Campbell JA, Bishu KG, Walker RJ, Egede LE. Trends of medical expenditures and quality of life in US adults with diabetes: the medical expenditure panel survey, 2002-2011. Health Qual Life Outcomes. 2017; 15:70

14. Kusi A, Hansen KS, Asante FA, Enemark U. Does the National Health Insurance Scheme provide financial protection to households in Ghana? BMC Health Serv Res. 2015;15:331.

15. Anbari Z, Mohammadbeigi A, Mohammadsalehi N, Ebrazeh A. Health expenditure and catastrophic costs for inpatient-and out-patient care in Iran. Int J Prev Med. 2014;5:1023.

16. Counts CJ, Skordis-Worrall J. Recognizing the importance of chronic disease in driving healthcare expenditure in Tanzania: analysis of panel data from 1991 to 2010. Health Policy Plan. 2015;31:434-43.

17. Organization for Economic Co-operation and Development: Health at a glance 2015: OECD indicators. OECD; 2015.

18. Woo KS, Shin YJ. The effect of catastrophic health expenditure on household economy: focusing on financial coping and poverty. Health Soc Welf Rev. 2015;35(3):166-98.

19. Xu K, World Health Organization. Distribution of health payments and catastrophic expenditures methodology. Geneva: World Health Organization; 2005.

20. Xu K, Evans DB, Kawabata K, Zeramdini R, Klavus J, Murray CJ. Household catastrophic health expenditure: a multicountry analysis. Lancet. 2003:362: $111-7$.

21. Ballinger GA. Using generalized estimating equations for longitudinal data analysis. Organ Res Methods. 2004;7:127-50.

22. Zorn CJ. Generalized estimating equation models for correlated data: a review with applications. Am J Polit Sci. 2001;45(2):470-90.

23. Li X, Shen JJ, Lu J, Wang Y, Sun M, Li C, Chang F, Hao M. Household catastrophic medical expenses in eastern China: determinants and policy implications. BMC Health Serv Res. 2013;13:1

24. Stein $\mathrm{CH}$, Hoffmann E, Bonar EE, Leith JE, Abraham KM, Hamill AC, Kraus SW, Gumber S, Fogo WR. The United States economic crisis: young adults' reports of economic pressures, financial and religious coping and psychological well-being. J Fam Econ Iss. 2013;34:200-10

25. Sobhonslidsuk A, Silpakit C, Kongsakon R, Satitpornkul P, Sripetch C, Khanthavit A. Factors influencing health-related quality of life in chronic liver disease. World J Gastroenterol. 2006:12:7786.

26. Kale HP, Carroll NV. Self-reported financial burden of cancer care and its effect on physical and mental health-related quality of life among US cancer survivors. Cancer. 2016;122:283-9.

27. Rogers SN, Harvey-Woodworth CN, Hare J, Leong P, Lowe D. Patients' perception of the financial impact of head and neck cancer and the relationship to health related quality of life. Br J Oral Maxillofac Surg. 2012;50:410-6.

28. Jeon $\mathrm{YH}$, Essue B, Jan S, Wells R, Whitworth JA. Economic hardship associated with managing chronic illness: a qualitative inquiry. BMC Health Serv Res. 2009:9:182

29. Megari K. Quality of life in chronic disease patients. Health Psychol Res. 2013;1:27

30. Kien VD, Van Minh H, Giang KB, Dao A, Tuan LT, Ng N. Socioeconomic inequalities in catastrophic health expenditure and impoverishment associated with non-communicable diseases in urban Hanoi, Vietnam. Int J Equity Health. 2016:15:169.

31. Arsenijevic J, Pavlova M, Rechel B, Groot W. Catastrophic health care expenditure among older people with chronic diseases in 15 European countries. PLoS One. 2016;11. 
32. Xu K, Evans DB, Carrin G, Aguilar-Rivera AM, Musgrove P, Evans T. Protecting households from catastrophic health spending. Health Aff. 2007;26:972-83.

33. Chuma J, Maina T. Catastrophic health care spending and impoverishment in Kenya. BMC Health Serv Res. 2012;12:1.

34. Bredenkamp C, Mendola M, Gragnolati M. Catastrophic and impoverishing effects of health expenditure: new evidence from the Western Balkans. Health Policy Plan. 2011;26:349-56.

35. Organization for Economic Co-operation and Development: Health at a glance 2013: OECD indicators. OECD; 2013.

36. Sun $\mathrm{S}$, Chen J, Johannesson M, Kind $P, X u L$, Zhang $Y$, Burstrom $K$. Population health status in China: EQ-5D results, by age, sex and socioeconomic status, from the National Health Services Survey 2008. Qual Life Res. 2011;20:309-20.

37. Konig HH, Bernert $\mathrm{S}$, Angermeyer MC, Matschinger $\mathrm{H}$, Martinez $\mathrm{M}$, Vilagut $\mathrm{G}$, Haro JM, de Girolamo G, de Graaf R, Kovess V, et al. Comparison of population health status in six european countries: results of a representative survey using the EQ-5D questionnaire. Med Care. 2009;47:255-61.

Ready to submit your research? Choose BMC and benefit from:

- fast, convenient online submission

- thorough peer review by experienced researchers in your field

- rapid publication on acceptance

- support for research data, including large and complex data types

- gold Open Access which fosters wider collaboration and increased citations

- maximum visibility for your research: over $100 \mathrm{M}$ website views per year

At $\mathrm{BMC}$, research is always in progress.

Learn more biomedcentral.com/submissions 